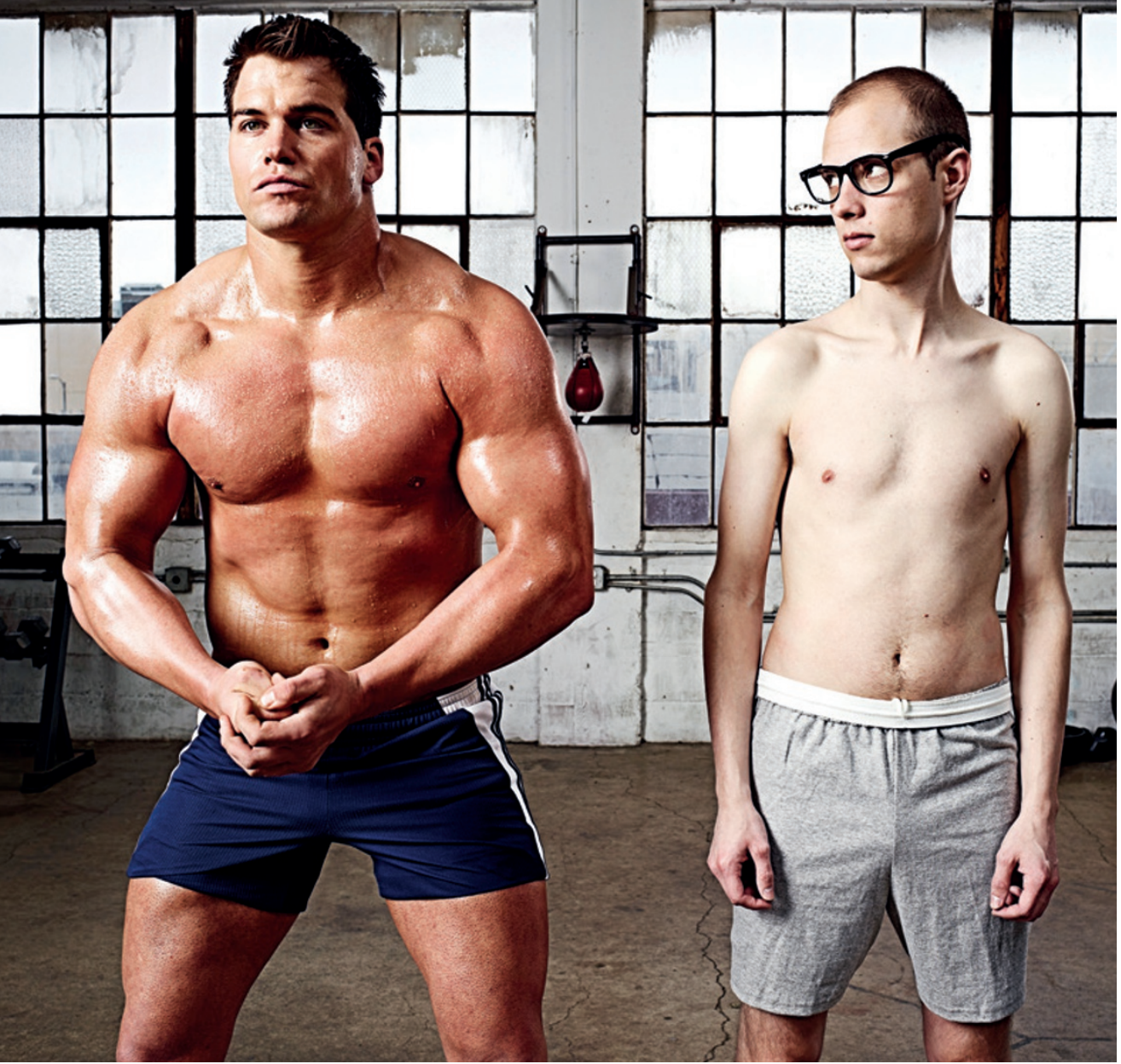

Faced with images of unrealistic ideals, men are increasingly concerned about their appearance.

MASCULINITY

Men's makeover

into their muscles to make them look larger or taking diet pills that contain the appetite suppressant ephedrine to lose weight. Body dissatisfaction can become an obsession and can lead to clinical disorders (see page S14). These negative feelings can also trigger symptoms of depression.

Research is starting to examine how men feel about their bodies, particularly when faced with images of masculinity in the media. A better understanding of how boys and men deal with insecurities about their appearance will help with the design of initiatives that are aimed at preventing unhealthy behaviours such as eating disorders. And, as studies suggest, this cannot come soon enough.

\title{
EVOLVING MANSCAPE
}

Psychological and social-sciences research into male body image has been around only for the past 15 years or so, says Phillippa Diedrichs, a health psychologist at the University of the West of England in Bristol, UK. But epidemiological studies are now starting to address the prevalence of concerns.

An almost two-decade-long study of US teenagers - the Growing Up Today Study, or GUTS - reported that nearly $18 \%$ of adolescent boys are highly concerned about their physical appearance ${ }^{2}$. Of the male respondents, $7.6 \%$ reported using muscle-building supplements, growth-hormone derivatives or anabolic steroids to achieve their ideal body. Although these behaviours do not fulfil the conventional eating-disorder criteria, they are risky actions that may be missed by paediatricians and parents, says Alison Field, an epidemiologist at Boston Children's Hospital in Massachusetts and one of the study's authors.

When GUTS began in 1996, research questionnaires for assessing body image in boys and men were not available. "Most of the large studies ask the same questions of males and females, with the assumption that if someone is concerned about their weight it looks the same," she says. The story is similar for Lina Ricciardelli, a psychologist at Deakin University in Victoria, Australia, who studies body-image issues. Only 20 years ago, she says, the prevailing wisdom was that men do not have these problems.

\section{UNDER THE INFLUENCE}

A host of factors have been tied to body-image issues in males. Men who are not dating, for example, tend to be more affected by media exposure than those who are. Sexual orientation plays a part as well. Compared with heterosexual men, gay men are more likely to express dissatisfaction with their appearance and are at greater risk of developing an eating disorder. The focus on appearance is ingrained in gay culture; gay media emphasizes unrealistically muscular and lean models to sell beauty products to an expanding and

Feeling bad about one's body is among the strongest predictors for developing an eating disorder, and one of the most modifiable. Interventions aimed at addressing such con more likely than men to have a recognizable more of the superhuman beauty ideals that to similarly unattainable standards.

costumes for boys feature chiselled abs, and health and beauty products for men line shop shelves. Sales of men's grooming products have skyrocketed across the globe over past few years. "Men are being addressed as consumers of health and beauty products and services in a very targeted way, in ways they haven't been historically," says Brendan Gough who studies men's body-image issues and masculinity at Leeds Beckett University, UK. According to Gough, some young men are thought to be injecting the oil synthol 
powerful consumer base.

The mainstream media exerts a powerful influence on body-image perception. For instance, one study found that male students in the United States viewing 30 minutes of television with commercials that feature muscle-bound men were more likely to report feeling depressed and dissatisfied with their own bodies compared with participants who watched television with neutral advertisements ${ }^{3}$. And a metaanalysis of 25 studies demonstrated a link between media exposure and measures of body dissatisfaction, low self-esteem and depression ${ }^{4}$. "The people more at risk are the ones who believe in the messages of the media," says Ricciardelli - they internalize the values promoted by television and magazines, believing them to reflect reality.

The way that men manage their masculinity is important for understanding and addressing their body-image concerns, says psychologist Viren Swami of the University of Westminster in London. His work centres on the idea that when some men feel their masculinity is threatened - for instance,

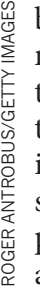

by the idea of gender equality or more-discrete events, such as being turned down for a date - they try to reassert some of that masculinity in the gym. He is in the early stages of examining whether the promotion of more-egalitarian attitudes between men helps to address their bodyimage concerns.

Although what is considered masculine behaviour has become more flexible of late (for example, new fathers now take on more domestic duties than before), men often do not consider grooming and dieting to be part of a traditional masculine role, says Gough. Instead, men hoping to lose weight say they want to become fit and strong. And straight men who wear make-up say that they use it because it will help them to attract women or be more successful at their jobs 5 .

\section{MEASURES FOR MEN}

One common way to measure body-image dissatisfaction is to show a study participant drawings of variously sized figures, and then to ask him to pick out

A classic example of masculinity Michelangelo's David. drawings that represent his current body size and his ideal size. The bigger the difference between the two, the more dissatisfied a person is with his body. Software has lent more precision to this measure by allowing people to see themselves on a projected screen and to adjust their bodies to their ideal, says psychologist Rick Gardner, a body-image perception specialist at the University of Colorado in Denver.

Body image is more

than just a one-off result. It is constantly changing, not as a result of any one individual characteristic, but with changing cultural and societal pressures, says Glen Jankowski, who is part of Gough's group at Leeds Beckett.

Even as masculinity norms become more flexible, men may feel less able than women to discuss body-image and emotional issues. However, in research at least, male participants do willingly talk about bodyimage concerns, says Engeln. At the outset of her research, she says, "we had some concerns that even if men did engage in something like fat talk, they wouldn't openly admit it. But our initial survey results showed us that men were quite open to talking about their body concerns, and many readily admitted having body-focused conversations with other men."

\section{ADAPTING THE INTERVENTION}

Body image is realized surprisingly early in life. Children as young as 5 years can develop a negative body image, according to Ricciardelli. That is why it is important to reach them while they are young, she says. She and others, including Swami, are developing programmes that promote an appreciation of what the human body can do, for example through physical activities such as contemporary dance.

Body-image programmes for boys are based on lesssolid scientific foundations than those for girls, says Diedrichs. There is no single standout programme that has been consistently shown to be effective for boys, she adds. Diedrichs, Jankowski and their colleagues are adapting a popular and effective intervention for women - the Succeed Body Image Programme, known in the United States as the Body Project - for use in men. So far, the data look promising, Jankowski says: at 3-month follow-ups, the men who took part in 2-day workshops felt better about their bodies and were less worried about their muscularity and body fat. Less clear from the researchers' initial studies, however, was the effectiveness of this programme when it was adapted for adolescent boys.

In developing an approach for Israeli teenagers, Moria Golan of the Hebrew University of Jerusalem knew that the US and UK discussion-based programmes would not suffice, in part because Israelis already openly discuss body image. Her group developed the In Favor of Myself wellness programme, which consists of 8 sessions, each lasting 90 minutes, that use games and interaction to build self-esteem through qualities other than appearance.

In a study of children aged 12 to 14 years, Golan and her colleagues found that girls gained more from the programme than boys ${ }^{6}$. The researchers have since developed a boyfriendly programme and are now testing it, with mixed results. Whether the group is male only or mixed gender, differences in the children's ethnicities, and whether the intervention is delivered by a teacher, or an outsider can all factor in a programme's effectiveness, she says.

Body-image concerns are closely tied to cultural and societal pressures. Young white men living in North American, European or Australian cities have been the focus of most studies, but what researchers learn from these men may not apply to all ethnic groups, or to boys and men living in developing countries who are increasingly exposed to Western media and ideals. Research, however, is expanding to include these groups.

In the meantime, thinking bigger than group interventions and trying to effect change in a society that promotes unrealistic ideals can be overwhelming. "We need to help young people become more savvy that they're heavily marketed to," Field says. "There's a whole industry out there that does not want you to feel good about yourself." Women have been coming to grips with this for generations. Now men are learning to deal with this manufactured inadequacy.

Kelly Rae Chi is a freelance science writer based in Cary, North Carolina.

1. Engeln, R., Sladek, M. R. \& Waldron, H. Body Image 10,300-308 (2013)

2. Field, A. E. et al. JAMA Pediatr. 168, 34-39 (2014)

3. Agliata, D. \& Tantleff-Dunn, S. J. Social Clin. Psychol. 23, 7-22 (2004)

4. Barlett, C. P., Vowels, C. L. \& Saucier, D. A. J. Social Clin. Psychol. 27, 279-310 (2008).

5. Hall, M., Gough, B. \& Seymour-Smith, S. J. Men's Stud. 20, 209-226 (2012).

6. Golan, M., Hagay, N. \& Tamir, S. PLoS ONE 9, e91778 (2014) 